\title{
Efficacy of different urinary uric acid indicators in patients with chronic kidney disease
}

\author{
Haochen Guan ${ }^{1,2}$, Yuqi Zheng ${ }^{1,2}$, Xun Zhou ${ }^{1,2}$, Ying Xu ${ }^{1,2}$, Chensheng Fu ${ }^{1,2}$, Jing Xiao ${ }^{1,2^{*}}$ and Zhibin Ye $e^{1,2^{*}}$ (D)
}

\begin{abstract}
Background: Mounting studies have shown that hyperuricemia is related to kidney diseases through multiple ways. However, the application of urinary uric acid indicators in patients with reduced renal function is not clear. In this study, we aim to determine the effects of renal function on various indicators reflecting uric acid levels in patients with chronic kidney disease (CKD).
\end{abstract}

Methods: Anthropometric and biochemical examinations were performed in 625 patients with CKD recruited from Dept of Nephrology of Huadong hospital affiliated to Fudan University. Multiple regression analyses were used to study correlations of the estimated glomerular filtration rate (eGFR) with serum uric acid (SUA) and renal handling of uric acid. For further study, smooth curve plots and threshold effect analyses were applied to clarify associations between renal function and uric acid levels.

Results: The nonlinear relationships were observed between eGFR and urinary uric acid indicators. The obvious inflection points were observed in smooth curve fitting of eGFR and fractional excretion of uric acid (FEur), excretion of uric acid per volume of glomerular filtration (EurGF). In subsequent analyses where levels of eGFR $<15$ $\mathrm{mL} / \mathrm{min} / 1.73 \mathrm{~m}^{2}$ were dichotomized (CKD5a/CKD5b), patients in the CKD5a showed higher levels of FEur and EurGF while lower levels of urinary uric acid excretion (UUA), clearance of uric acid (Cur) and glomerular filtration load of uric acid (FLur) compared with CKD5b group (all $P<0.05$ ). And there was no significant difference of SUA levels between two groups. On the other hand, when eGFR< $109.9 \mathrm{ml} / \mathrm{min} / 1.73 \mathrm{~m}^{2}$ and $89.1 \mathrm{ml} / \mathrm{min} / 1.73 \mathrm{~m}^{2}$, the resultant curves exhibited approximately linear associations of eGFR with Cur and FLur respectively.

Conclusion: FEur and EurGF showed significantly compensatory increases with decreased renal function. And extrarenal uric acid excretion may play a compensatory role in patients with severe renal impairment to maintain SUA levels. Moreover, Cur and FLur may be more reliable indicators of classification for hyperuricemia in CKD patients.

Keywords: Chronic kidney disease, Serum uric acid, Urinary uric acid indicators, Renal function

\footnotetext{
*Correspondence: jingxiao13@fudan.edu.cn; yezhibin3@126.com

'Department of Nephrology, Huadong Hospital affiliated to Fudan University,

No. 221 West Yan'an Road, Shanghai 200040, P.R. China

Full list of author information is available at the end of the article
}

(C) The Author(s). 2020 Open Access This article is licensed under a Creative Commons Attribution 4.0 International License, which permits use, sharing, adaptation, distribution and reproduction in any medium or format, as long as you give appropriate credit to the original author(s) and the source, provide a link to the Creative Commons licence, and indicate if changes were made. The images or other third party material in this article are included in the article's Creative Commons licence, unless indicated otherwise in a credit line to the material. If material is not included in the article's Creative Commons licence and your intended use is not permitted by statutory regulation or exceeds the permitted use, you will need to obtain permission directly from the copyright holder. To view a copy of this licence, visit http://creativecommons.org/licenses/by/4.0/ The Creative Commons Public Domain Dedication waiver (http://creativecommons.org/publicdomain/zero/1.0/) applies to the data made available in this article, unless otherwise stated in a credit line to the data. 


\section{Background}

Hyperuricemia is a disease characterized by abnormal elevation of serum uric acid (SUA), defined as SUA level $\geq$ $6.8 \mathrm{mg} / \mathrm{dL}$ based on the limit of urate solubility, which is closely related to the occurrence and development of renal diseases [1, 2]. It has demonstrated that hyperuricemia is an independent risk factor for the decline in renal function, and the incidence of hyperuricemia increases with the progression of estimated glomerular filtration rate (eGFR) staging [3-5]. Regardless of which is cause or consequence, the correlation between chronic kidney disease (CKD) and hyperuricemia became apparent [6]. Previous studies revealed the phenomenon that apart from excessive production of uric acid more than $90 \%$ of hyperuricemia is caused by the inefficient capacity of renal to clear uric acid [7]. It was believed that renal handling of uric acid mainly relied on absorption, secretion and reabsorption of renal tubules. However, a cross-sectional study revealed that glomerular function played a more important role in regulating uric acid homeostasis than previously thought [8]. This study showed that the prevalence of gout was $2.9 \%$ among those with normal GFR while $24 \%$ among those with GFR $<60 \mathrm{ml} / \mathrm{min} / 1.73 \mathrm{~m}^{2}$ and the prevalence of gout increased by about 2-3 times for every 30 $\mathrm{ml} / \mathrm{min} / 1.73 \mathrm{~m}^{2}$ decrease in GFR. In addition, it has been proved that multiple uric acid transporters are expressed at the apical and basolateral membranes of proximal tubule which coupled with numerous solutes to regulate uric acid influx and efflux. Due to the abnormal activation of renin-angiotensin-aldosterone system (RAAS) and parathyroid hormone (PTH) of CKD, ANG II and PTH stimulate the coupled entry of $\mathrm{Na}+$ and lactate which in turn increase urate/lactate exchange across urate transporter 1 (URAT1) causing reduced uric acid excretion [9]. Therefore, the reduced glomerular filtration and deregulated RAAS and PTH in maintaining the balance of uric acid in CKD must not be ignored. According to different combinations of urinary uric acid excretion (UUA), clearance of uric acid (Cur) and fractional excretion of uric acid (FEur), hyperuricemia can be divided into three categories: urate overproduction, decreased uric acid excretion and combined mechanism which is helpful to instruct application of urate-lowering drugs reasonably and clarify the metabolic status of uric acid in patients [10]. However, the current classification of hyperuricemia did not take renal function into account, which may affect the accurate assessment of uric acid excretion in CKD patients. As we know, the specific mechanism underlying how renal function affects uric acid excretion in the population with CKD is rarely studied. Thus, this study aims to investigate the efficacy of different urinary uric acid indicators in patients with CKD and determine the excretion of uric acid in CKD patients.
In clinical practice, the most common method to classify hyperuricemic patients is measuring urinary uric acid output per day to evaluate whether underexcretion of uric acid or not. Patients with UUA $>800 \mathrm{mg} / \mathrm{d}$ on a regular diet suggests overproduction of uric acid as the etiology [11]. However, the traditional indicator of uric acid excretion such as UUA is easily affected by many factors (for example, SUA, urine volume, serum creatinine, gender, weight) and cannot accurately reflect the excretion of uric acid of renal tubules. Perez-Ruiz [12] found that even patients with gout showing apparent high uric acid output per day showed lower Cur than controls through a case-control study, indicating that relative, low-grade underexcretion of uric acid actually. And some new parameters of uric acid are more persuasive and less to be distributed such as Cur, FEur, glomerular filtration load of uric acid (FLur), excretion of uric acid per volume of glomerular filtration (EurGF). Therefore, we analyze these indicators to confirm which parameter is superior to assess the excretion of uric acid in CKD patients.

\section{Methods}

Study population and sample collection

A total of 625 consecutive patients with CKD from 2015 to 2018 hospitalized in Department of Nephrology, Huadong hospital affiliated to Fudan University (Shanghai, P.R.China) were included in this study for analysis. Clinical indicators of patients needed to be stable during the study period and demanding normal purine diet without alcohol or rich fructose food for 5 days before the study. Patients were excluded according to the following exclusion criteria: taking medications known to affect renal handling of uric acid (such as aspirin, anti-tuberculosis drugs, immunosuppressive agents, diuretics, losartan, metformin) and uric acid-lowering agents (such as allopurinol, febuxostat, benzbromarone) in the previous 2 weeks; acute kidney injury, kidney transplantation, dialysis; a history of hereditary hyperuricemia; severe heart, lung or liver dysfunction, infection and tumor.

\section{Clinical measurements}

The clinical data were extracted from the medical records of 625 CKD patients. Fasting blood samples were drawn in the morning and all patients underwent renal function tests using 24-h urine collection while on an unrestricted diet (avoiding excessive purine and fructose intake and with avoidance of alcohol). All samples were immediately sent to the laboratory for the biochemical analysis including hemoglobin (HB), C-reactive protein (CRP), hemoglobin A1c (HbA1c), albumin (ALB), lowdensity lipoprotein (LDL), high-density lipoprotein (HDL), total cholesterol (TC), triglycerides (TG), blood 
urea nitrogen $(\mathrm{BUN})$, serum creatinine $(\mathrm{Scr})$, serum uric acid (SUA).

Body mass index (BMI) was calculated from formula $\mathrm{BMI}=$ weight $/$ height $^{2}$, expressed in $\mathrm{kg} / \mathrm{m}^{2}$. Urinary uric acid (UUA) represented twenty-four hours uric acid was calculated as uric acid concentration $\times 24$-h urinary volume (24-h UV). Urinary creatinine (Ucr) represented twenty-four hours urinary creatinine calculated as urinary creatinine concentration $\times 24-h$ UV. Clearance of creatinine $(\mathrm{Ccr})$ was calculated as urinary creatinine concentration $\times 24$-h UV / Scr, expressed in $\mathrm{ml} / \mathrm{min}$. The formula of clearance of uric acid (Cur) was urinary uric acid concentration $\times 24-\mathrm{h}$ UV / SUA, expressed in $\mathrm{ml} /$ min. Glomerular filtration load of uric acid (FLur) was calculated as $\mathrm{Ccr} \times \mathrm{SUA}$, expressed in $\mu \mathrm{mol} / \mathrm{min}$. Fractional excretion of uric acid (FEur) was calculated as $(\mathrm{UUA} \times \mathrm{Scr}) /(\mathrm{SUA} \times \mathrm{Ucr}) \times 100$, expressed as percentage. Excretion of uric acid per volume of glomerular filtration $($ EurGF) was calculated as $(\mathrm{UUA} \times \mathrm{Scr}) / \mathrm{Ucr}$, expressed in $\mu \mathrm{mol} / \mathrm{L}$. The estimated glomerular filtration rate $(\mathrm{eGFR})\left(\mathrm{mL} / \mathrm{min} / 1.73 \mathrm{~m}^{2}\right)$, an indicator of renal function, was calculated using the Chronic Kidney Disease Epidemiology Collaboration (CKD-EPI) formula.

\section{Grouping criteria}

According to the Kidney Disease: Improving Global Outcomes CKD guidelines, we divided patients into 5 groups based on levels of eGFR, eGFR categories were defined as follows: $\geq 90 \mathrm{~mL} / \mathrm{min} / 1.73 \mathrm{~m}^{2}$ (CKD1), $60-89$ $\mathrm{mL} / \mathrm{min} / 1.73 \mathrm{~m}^{2} \quad$ (CKD2), $\quad 30-59 \mathrm{~mL} / \mathrm{min} / 1.73 \mathrm{~m}^{2}$ (CKD3), $\quad 15-29 \mathrm{~mL} / \mathrm{min} / 1.73 \mathrm{~m}^{2}$ (CKD4) and $<15 \mathrm{~mL} /$ $\mathrm{min} / 1.73 \mathrm{~m}^{2}$ (CKD5). According to the inflection points of FEur and EurGF, we divided patients with CKD5 into CKD5a: $\quad 7.5 \mathrm{~mL} / \mathrm{min} / 1.73 \mathrm{~m}^{2} \leq \mathrm{eGFR}<15 \mathrm{~mL} / \mathrm{min} /$ $1.73 \mathrm{~m}^{2}$ and CKD5b: eGFR $<7.5 \mathrm{~mL} / \mathrm{min} / 1.73 \mathrm{~m}^{2}$.

\section{Statistical analysis}

Data are presented as mean \pm standard deviation (SD), median with inter quartile range (IQR) or percentages for normally distributed continuous variables, non-normally distributed continuous variables and categorical variables, respectively. The distribution of all examined variables was assessed by Shapiro-Wilk test, histograms and probability plots. T test was used between the two groups, and One-way ANOVA was used to compare normally distributed data. We used Kruskall-Wallis test to compare nonnormally distributed data and Chi-square test for categorical data. Then we applied multiple regression analyses to determine the independent associations between renal function and uric acid levels (including SUA, UUA, Cur, FLur, FEur, EurGF), with an adjustment for multiple confounding factors. And we further applied a two-piecewise linear regression model to examine the threshold effect of the eGFR on uric acid levels using a smoothing function.
Likelihood ratio tests were conducted to compare the one-line linear regression model with a two-piecewise linear model. Statistical significance was set at $P<0.05$. All statistical analysis was performed with EmpowerStats (www.empowerstats.com), the statistical package R, software SPSS 23.0 and GraphPad Prism 7.0.

\section{Results}

Baseline characteristics of the study population stratified by levels of eGFR

Based on the exclusion criteria, 625 CKD patients (318 males and 307 females) aged $57.9 \pm 16.4$ years were selected into the current study. General data and functional parameters in different groups according to levels of eGFR are shown in Table 1. The mean level of SUA was $393.8 \mu \mathrm{mol} / \mathrm{L}$ and the median UUA level was 2.3 $\mathrm{mmol} / 24 \mathrm{~h}$. And various indicators for evaluating uric acid levels (including SUA, UUA, Cur, FLur, EurGF, FEur) were significantly different in different groups. It seems to conclude that patients with worse renal function show higher levels of SUA, FEur, EurGF while lower level of UUA, Cur and FLur. Apart from uric acid indicators, other clinical parameters such as age, ratio of hypertension, ratio of diabetes, HB, CRP, ALB, LDL, HDL, TC, BUN, Scr, Ucr, and Ccr were all significantly different among groups.

Normally distributed variables are presented as mean \pm SD. For non-normally distributed data such as CRP, UUA, Ccr, Cur, FLur, EurGF and FEur, medians and the 25th and 75th percentiles are shown. Categorical variables are presented as percentages. $P$ values are assessed with one-way ANOVA, Kruskal-Wallis or Chi-square test, as appropriate. Bold indicates statistical significance $(P$ value $<0.05)$.

\section{Association of renal function with uric acid levels}

We applied multiple regression models to examine association of renal function with SUA, UUA, Cur, FLur, EurGF and FEur using eGFR as a continuous variable and in categories (Table 2). When we examined eGFR as a continuous variable, we found inverse associations with SUA, FEur, EurGF $(\beta=-1.41,95 \% \mathrm{CI}:-1.64,-1.17$; $\beta=-0.15,95 \%$ CI: $-0.16,-0.13$ and $\beta=-0.76,95 \%$ CI: $0.84,-0.67$, respectively) and positive correlation with UUA, Cur, FLur $(\beta=0.01,95 \%$ CI: $0.01,0.02 ; \beta=0.04$, 95\%CI: $0.04,0.05$ and $\beta=0.33,95 \% \mathrm{CI}: 0.29,0.36$, respectively) after adjusting for potential confounders (all $P<$ 0.01). With eGFR cutoffs, patients in CKD2-CKD5 stage had higher SUA levels and lower Cur and FLur levels compared with CKD1 stage patients (all $P<0.01$ ). And CKD3-5 stage patients showed lower levels of UUA and higher levels of FEur and EurGF compares with CKD1 patients (all $P<0.01$ ) with the adjustment of multiple confounders. 
Table 1 Baseline characteristics of the study population stratified by levels of eGFR

\begin{tabular}{|c|c|c|c|c|c|c|c|}
\hline Variables & $\begin{array}{l}\text { Overall } \\
(n=625)\end{array}$ & $\begin{array}{l}\text { CKD1 } \\
(n=130)\end{array}$ & $\begin{array}{l}\text { CKD2 } \\
(n=164)\end{array}$ & $\begin{array}{l}\text { CKD3 } \\
(n=147)\end{array}$ & $\begin{array}{l}\text { CKD4 } \\
(n=86)\end{array}$ & $\begin{array}{l}\text { CKD5 } \\
(n=97)\end{array}$ & $P$ value \\
\hline Male gender (\%) & 50.9 & 50.8 & 56.7 & 45.6 & 48.8 & 50.5 & 0.4021 \\
\hline Age (years) & $57.9 \pm 16.4$ & $46.2 \pm 14.9$ & $56.4 \pm 14.7$ & $62.4 \pm 15.4$ & $63.8 \pm 15.4$ & $63.9 \pm 14.8$ & $<0.001$ \\
\hline BMI $\left(\mathrm{kg} / \mathrm{m}^{2}\right)$ & $24.3 \pm 3.9$ & $23.7 \pm 3.8$ & $24.7 \pm 4.4$ & $24.7 \pm 3.5$ & $24.2 \pm 3.7$ & $24.1 \pm 4.0$ & 0.204 \\
\hline Hypertension (\%) & 66.8 & 32.1 & 61.3 & 76.2 & 83.6 & 83.8 & $<0.0001$ \\
\hline Diabetes (\%) & 32 & 19.2 & 29 & 38.1 & 29.5 & 43.8 & 0.0118 \\
\hline $\mathrm{HB}(\mathrm{g} / \mathrm{L})$ & $115.9 \pm 24.4$ & $128.6 \pm 18.3$ & $131.1 \pm 19.2$ & $122.3 \pm 17.7$ & $102.7 \pm 17.9$ & $90.3 \pm 18.7$ & $<0.001$ \\
\hline CRP (mg/L) & $3.7(1.1-8.2)$ & $2.8(0.8-6.2)$ & $3.2(1.0-6.5)$ & $3.8(1.1-9.5)$ & $4.7(1.2-9.0)$ & $6.0(1.8-12.2)$ & $<0.001$ \\
\hline $\mathrm{HbA1C}(\%)$ & $6.0 \pm 1.1$ & $6.0 \pm 1.5$ & $6.0 \pm 0.9$ & $6.2 \pm 1.1$ & $6.1 \pm 1.0$ & $5.9 \pm 1.0$ & 0.637 \\
\hline ALB (g/L) & $37.8 \pm 7.6$ & $38.2 \pm 7.6$ & $38.8 \pm 9.7$ & $38.6 \pm 6.4$ & $36.7 \pm 6.6$ & $35.5 \pm 5.5$ & 0.004 \\
\hline LDL (mmol/L) & $2.8 \pm 1.1$ & $3.1 \pm 1.2$ & $3.0 \pm 1.3$ & $2.7 \pm 0.9$ & $2.7 \pm 1.0$ & $2.4 \pm 0.8$ & $<0.001$ \\
\hline $\mathrm{HDL}$ (mmol/L) & $1.3 \pm 0.4$ & $1.4 \pm 0.3$ & $1.3 \pm 0.4$ & $1.3 \pm 0.4$ & $1.3 \pm 0.3$ & $1.2 \pm 0.3$ & 0.003 \\
\hline TC (mmol/L) & $4.9 \pm 1.5$ & $5.1 \pm 1.7$ & $5.1 \pm 1.7$ & $4.7 \pm 1.4$ & $4.9 \pm 1.5$ & $4.4 \pm 1.1$ & 0.002 \\
\hline TG (mmol/L) & $1.9 \pm 1.4$ & $1.9 \pm 1.3$ & $2.0 \pm 1.8$ & $1.9 \pm 1.1$ & $2.1 \pm 1.7$ & $1.6 \pm 0.8$ & 0.188 \\
\hline BUN (mmol/L) & $10.5 \pm 8.2$ & $4.9 \pm 1.3$ & $6.6 \pm 5.1$ & $8.5 \pm 2.7$ & $13.2 \pm 4.6$ & $24.9 \pm 8.4$ & $<0.001$ \\
\hline $\operatorname{Scr}(\mu \mathrm{mol} / \mathrm{L})$ & $199.0 \pm 218.6$ & $63.5 \pm 11.5$ & $89.8 \pm 15.6$ & $134.9 \pm 28.5$ & $227.5 \pm 43.7$ & $631.6 \pm 250.3$ & $<0.001$ \\
\hline SUA ( $\mu \mathrm{mol} / \mathrm{L})$ & $393.8 \pm 110.7$ & $329.1 \pm 89.3$ & $367.1 \pm 102.2$ & $423.6 \pm 96.5$ & $414.8 \pm 106.6$ & $461.0 \pm 116.7$ & $<0.001$ \\
\hline UUA (mmol/24 h) & $2.3(1.7-3.1)$ & $2.9(2.3-3.6)$ & $2.7(2.2-3.4)$ & $2.3(1.7-2.8)$ & $1.8(1.3-2.4)$ & $1.4(0.8-1.9)$ & $<0.001$ \\
\hline $\mathrm{Ccr}(\mathrm{mL} / \mathrm{min})$ & $60.1(26.7-93.1)$ & $114.3(92.9-135.6)$ & $83.2(69.3-101.7)$ & $52.0(43.0-65.2)$ & $26.4(20.8-35.1)$ & $9.3(5.9-14.3)$ & $<0.001$ \\
\hline Cur (mL/min) & $4.3(2.7-6.0)$ & $6.6(4.6-8.6)$ & $5.2(4.2-6.9)$ & $3.8(3.0-4.9)$ & $2.9(2.2-4.4)$ & $2.0(1.3-2.7)$ & $<0.001$ \\
\hline FLur ( $\mu \mathrm{mol} / \mathrm{min})$ & $22.3(10.9-33.1)$ & $38.2(26.9-47.6)$ & $30.7(22.4-41.8)$ & $22.2(16.2-26.8)$ & $11.2(7.6-15.9)$ & $4.1(2.7-6.3)$ & $<0.001$ \\
\hline EurGF ( $\mu \mathrm{mol} / \mathrm{L})$ & $26.7(20.2-46.1)$ & $18.0(15.2-20.7)$ & $22.4(19.8-27.1)$ & $29.2(23.6-37.6)$ & $50.6(35.7-58.6)$ & $91.2(67.0-135.4)$ & $<0.001$ \\
\hline FEur (\%) & $7.3(5.5-11.3)$ & $5.5(4.3-7.1)$ & $6.1(5.1-7.6)$ & $7.3(5.8-9.2)$ & $11.1(7.9-15.3)$ & $20.7(15.6-29.7)$ & $<0.001$ \\
\hline
\end{tabular}

Multiple regression analyses were used to estimate associations of renal function with uric acid after adjusting for age, height, weight, body surface area. Values reflect the difference and 95\% CI for categories of eGFR as compared with the reference category. Values for eGFR continuously reflect a difference per $\mathrm{mL} / \mathrm{min} / 1.73 \mathrm{~m}^{2}$ in levels of eGFR. CKD1: eGFR $\geq 90 \mathrm{~mL} / \mathrm{min} / 1.73 \mathrm{~m}^{2}$, CKD2: $89 \geq \mathrm{eGFR} \geq 60$ $\mathrm{mL} / \mathrm{min} / 1.73 \mathrm{~m}^{2}$, CKD3: $59 \geq \mathrm{eGFR} \geq 30 \mathrm{~mL} / \mathrm{min} / 1.73 \mathrm{~m}^{2}$, CKD4: $29 \geq \mathrm{eGFR} \geq 15 \mathrm{~mL} / \mathrm{min} / 1.73 \mathrm{~m}^{2}$, CKD5: eGFR < 15 $\mathrm{mL} / \mathrm{min} / 1.73 \mathrm{~m}^{2}$. $P<0.05,{ }^{* * *} P<0.01$.

\section{Smooth curve fitting and threshold effect analysis of eGFR on uric acid levels}

Smooth curve plots were performed after the adjustment of confounding factors, and the resultant curves exhibited nonlinear associations of eGFR with SUA, UUA, Cur and FLur. In addition, two-stage changes and inflection points were observed in FEur and EurGF, and different inflection points appeared according to gender grouping (Fig. 1). The levels of FEur and EurGF increased with decreasing eGFR values up to the inflection points $\left(15.9 \mathrm{~mL} / \mathrm{min} / 1.73 \mathrm{~m}^{2}\right.$ and

Table 2 Adjusted effects of renal function on levels of uric acid

\begin{tabular}{|c|c|c|c|c|c|}
\hline $\operatorname{All}(n=625)$ & $\begin{array}{l}\text { SUA }(\mu \mathrm{mol} / L) \beta \\
(95 \% \mathrm{Cl})\end{array}$ & $\begin{array}{l}\text { UUA (mmol/24 h) } \beta \\
(95 \% \mathrm{Cl})\end{array}$ & $\begin{array}{l}\text { Cur }(\mathrm{mL} / \mathrm{min}) \beta \\
(95 \% \mathrm{Cl})\end{array}$ & $\begin{array}{l}\text { FLur }(\mu \mathrm{mol} / \mathrm{min}) \beta \\
(95 \% \mathrm{Cl})\end{array}$ & $\begin{array}{l}\text { FEur (\%) } \beta \\
(95 \% \mathrm{Cl})\end{array}$ \\
\hline $\begin{array}{l}\text { Continuous eGFR } \\
\left(\mathrm{mL} / \mathrm{min} / 1.73^{2}\right)\end{array}$ & $-1.41(-1.64,-1.17)^{* *}$ & $0.01(0.01,0.02)^{* *}$ & $0.04(0.04,0.05)^{* *}$ & $0.33(0.29,0.36)^{* *}$ & $-0.15(-0.16,-0.13)^{* *}$ \\
\hline \multicolumn{6}{|l|}{ Clinical cutoffs } \\
\hline CKD $1(n=130)$ & Reference & Reference & Reference & Reference & Reference \\
\hline $\operatorname{CKD} 2(n=164)$ & $35.36(12.13,58.59)$ & $-0.17(-0.50,0.17)$ & $-1.02(-1.78,-0.27)$ & $-6.13(-9.68,-2.59)^{* *}$ & $1.23(-0.51,2.96)$ \\
\hline CKD $3(n=147)$ & $99.55(74.95,124.16)^{* *}$ & $-0.43(-0.78,-0.07)^{*}$ & $-2.49(-3.29,-1.70)^{* *}$ & $-15.93(-19.68,-12.17)^{* *}$ & $2.80(0.95,4.65)^{* *}$ \\
\hline CKD $4(n=86)$ & $99.08(71.00,127.17)^{* *}$ & $-0.87(-1.27,0.46)^{* *}$ & $-3.32(-4.24,-2.41)^{* *}$ & $-24.80(-29.09,-20.52)^{* *}$ & $6.58(4.47,8.69)^{* *}$ \\
\hline CKD $5(n=97)$ & $146.02(118.80,173.25)^{* *}$ & $-1.41(-1.80,1.01)^{* *}$ & $-4.59(-5.47,-3.70) * *$ & $-32.01(-36.17,-27.85)^{* *}$ & $17.41(15.37,19.46)^{* *}$ \\
\hline
\end{tabular}




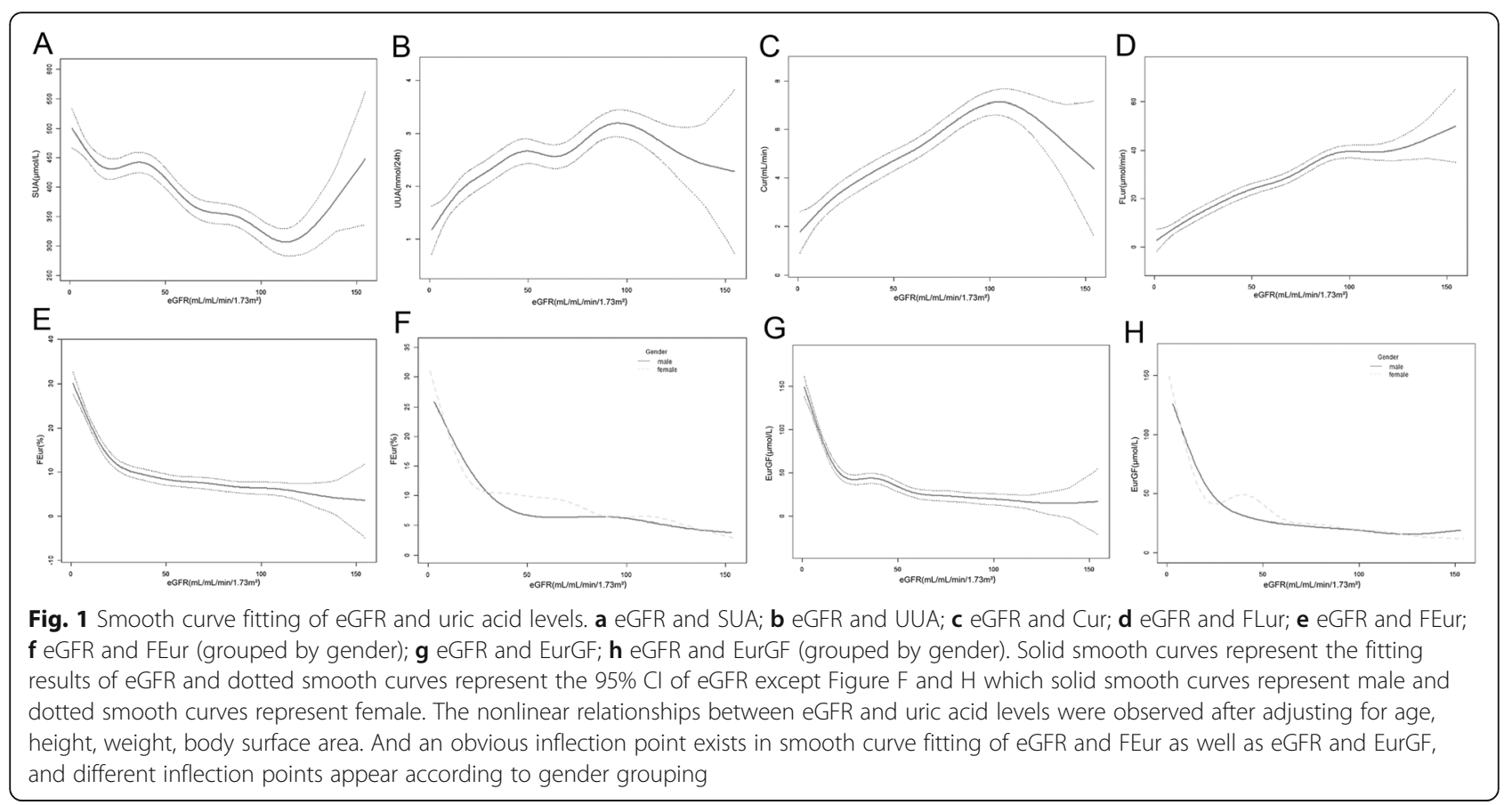

$15.3 \mathrm{~mL} / \mathrm{min} / 1.73 \mathrm{~m}^{2}$, respectively) with or without the adjustment of potential confounders. When the eGFR values were less than the points, the FEur and EurGF levels presented dramatical decrease $(\beta=-1.4,95 \% \mathrm{CI}$ : $-1.6,-1.2, P<$ 0.001 and $\beta=-7.6,95 \% \mathrm{CI}:-8.5,-6.7, P<0.001)$; in contrast, if the values were more than the points, the FEur and EurGF levels showed mild decrease $(\beta=-0.1,95 \% \mathrm{CI}$ : $0.1,-0.0, \quad P<0.001$ and $\beta=-0.4,95 \% \mathrm{CI}:-0.5,-0.3, \quad P<$ $0.001)$. The threshold effects were also analyzed based on gender grouping. The data indicated that the inflection point of FEur was $28.9 \mathrm{~mL} / \mathrm{min} / 1.73 \mathrm{~m}^{2}$ in male patients, 8 $\mathrm{mL} / \mathrm{min} / 1.73 \mathrm{~m}^{2}$ in female patients and the inflection point of EurGF was $20.2 \mathrm{~mL} / \mathrm{min} / 1.73 \mathrm{~m}^{2}$ in male patients, 13.9 $\mathrm{mL} / \mathrm{min} / 1.73 \mathrm{~m}^{2}$ in female patients after adjusting for confounders (Fig. 1 and Table 3). On the other hand, when eGFR $<109.9 \mathrm{ml} / \mathrm{min} / 1.73 \mathrm{~m}^{2}$ and $89.1 \mathrm{ml} / \mathrm{min} / 1.73 \mathrm{~m}^{2}$, the resultant curves exhibited approximately linear associations of eGFR with Cur and FLur respectively (Fig. 1).

The threshold effects were analyzed based on gender grouping. The data indicated that the inflection point of FEur and EurGF were different in male and female patients. Model I: no adjustment; Model II: adjusted for age, height, weight, body surface area.

$\beta$ represents beta coefficient which refers to how many deviations change in the dependent variable rely on the change of independent variable.

\section{Differences of various uric acid indicators in patients with CKD5}

According to the inflection points of FEur and EurGF, we divided all CKD5 stage patients into two groups
(CKD5a: $7.5 \mathrm{~mL} / \mathrm{min} / 1.73 \mathrm{~m}^{2} \leq \mathrm{eGFR}<15 \mathrm{~mL} / \mathrm{min} /$ $1.73 \mathrm{~m}^{2}$ and CKD5b: eGFR $<7.5 \mathrm{~mL} / \mathrm{min} / 1.73 \mathrm{~m}^{2}$ ). T test was used to compare levels of SUA while nonparametric tests were applied to compare UUA, Cur, FLur, FEur and EurGF levels. Compared with CKD5a group, levels of UUA, Cur and FLur were lower in CKD5b group $(P<0.01$; Fig. $2 \mathrm{~b}, \mathrm{c}, \mathrm{d})$. Levels of FEur and EurGF were significantly elevated in the CKD5b group vs. CKD5a group $(P<0.01$ and $P<0.05$ respectively; Fig. $2 \mathrm{e}, \mathrm{f})$. Interestingly, there was no significant difference of SUA levels between two groups (Fig. 2a).

\section{Discussion}

The level of SUA is closely related to the renal excretion of uric acid. Besides, pathological change, diet, gene mutation or medicine effects may affect the excretion of uric acid [13-16]. A number of studies have shown that reduction of uric acid excretion is harmful to various systems [17], while some recent studies have demonstrated that increased uric acid excretion may be one of the causes of acute and chronic kidney disease as well. As far as we know there are few studies on the assessment of renal uric acid excretion in CKD patients. Findings from the current analysis demonstrated that inversely nonlinear associations of eGFR with SUA, FEur and EurGF, and the positively nonlinear correlation between eGFR and UUA, Cur and FLur in CKD patients. And approximately linear associations of eGFR with Cur and FLur were observed when $\mathrm{eGFR}<109.9 \mathrm{ml} / \mathrm{min} / 1.73 \mathrm{~m}^{2}$ and $89.1 \mathrm{ml} / \mathrm{min} / 1.73 \mathrm{~m}^{2}$. The above results indicated that 


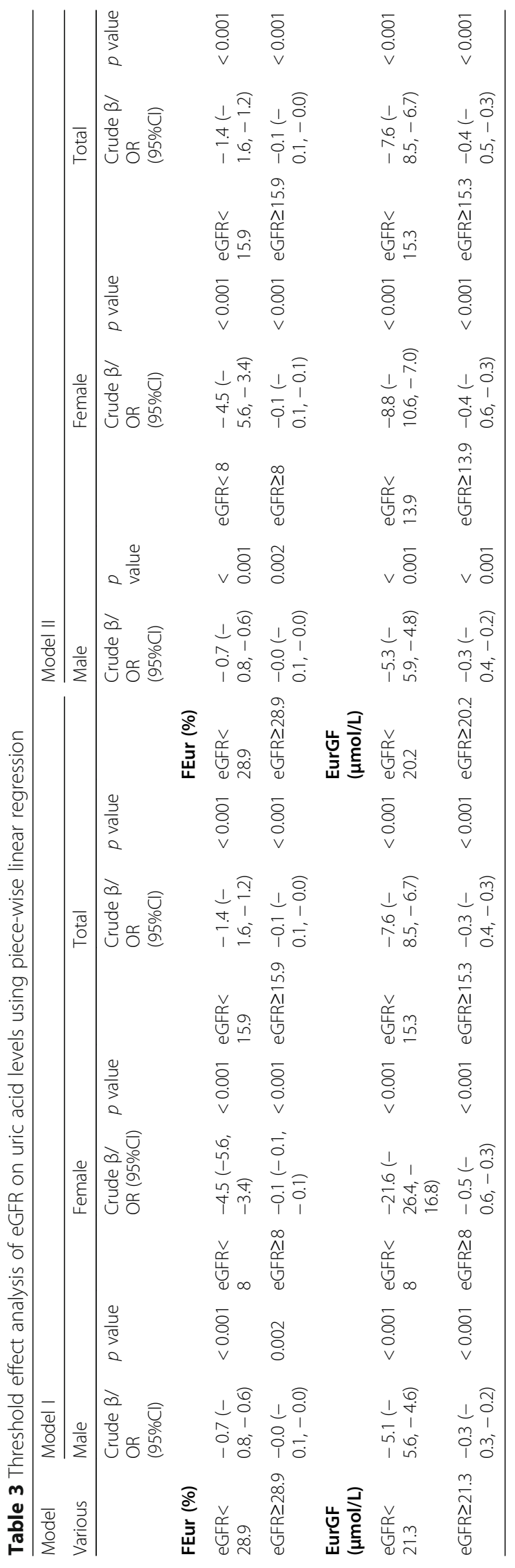




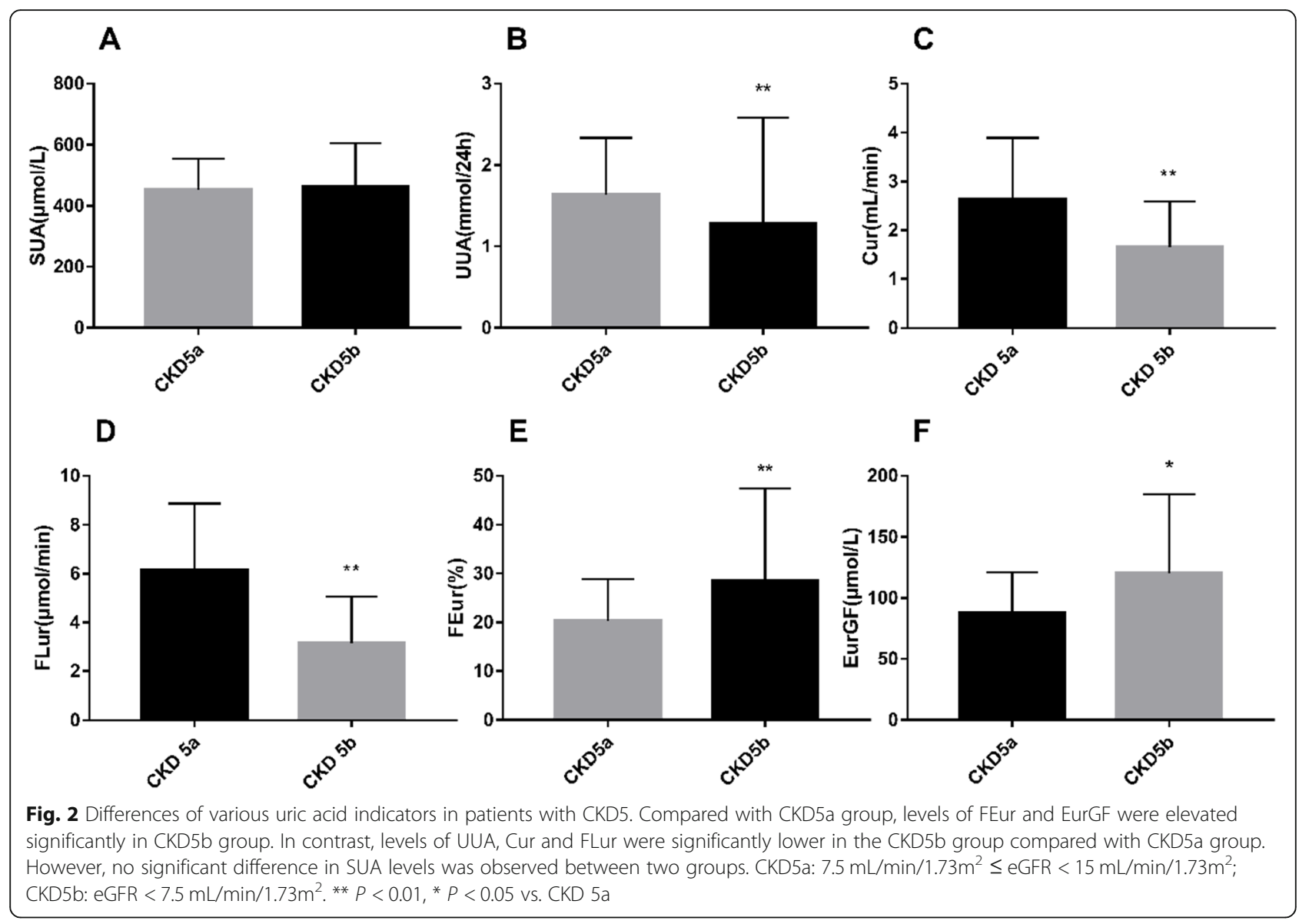

Cur and FLur are better parameters for monitoring uric acid metabolism in patients with renal dysfunction.

Although several studies have found that the association of SUA and UUA with the likelihood of CKD [18, 19] since these indicators are vulnerable to confounding factors, especially renal function, it seems insufficient to assess uric acid excretion in patients with CKD and to classify hyperuricemia based on them. And this view has been confirmed in our research. The previous study has shown that a good relationship between Cur and UUA was observed while a poor correlation between EurGF and UUA in gout patients with mild impairment of renal function. And Cur misclassified 15\% gout patients and EurFG misclassified 33\% patients when UUA, Cur and EurGF were used to classify gouty patients [20]. This result was compatible with ours that Cur may be a more constant indicator and reflected the intrinsic capacity for the renal handling of uric acid which was independent of renal function.

One prospective observational study found that compared with healthy controls, gout patients with eGFR > $60 \mathrm{ml} / \mathrm{min} / 1.73 \mathrm{~m}^{2}$ showed higher levels of FLur and lower Cur and FEur. And changes in FLur were correlated with changes in SUA levels significantly [21]. Moreover, it should be emphasized that EurGF and UUA didn't take SUA into account, thus omitting the effect of the FLur, and these indicators can be influenced by the FLur. In other words, the decline in CKD patient's eGFR level is itself accompanied by a different FLur level, while EurGF or UUA may be affected under the influence of different FLur levels and weaken their value in evaluating uric acid excretion status. FLur showed a good linear relationship with eGFR suggesting its important value in reflecting uric acid excretion status in CKD patients. Although more evidence is needed to support our view, our study provides a new understanding of the efficacy of different urinary uric acid indicators in patients with CKD.

In our study, we found two-stage changes and genderspecific inflection points in FEur and EurGF which suggest these two indicators should be used cautiously in CKD patients. Patients with eGFR $<7.5 \mathrm{~mL} / \mathrm{min} / 1.73 \mathrm{~m}^{2}$ (CKD5b) showed lower levels of UUA and higher level of FEur, EurGF while similar level of SUA compared to patients with $7.5 \mathrm{~mL} / \mathrm{min} / 1.73 \mathrm{~m}^{2} \leq \mathrm{eGFR}<15 \mathrm{~mL} / \mathrm{min} /$ $1.73 \mathrm{~m}^{2}$ (CKD5a), suggesting there may be the compensation of residual nephrons, extra-renal excretion or 
presently unknown factors of uremia per se affecting the entire dynamic metabolism of uric acid. We found that FEur and EurGF dramatically increased in CKD 5 patients and speculated there is an adaptive alteration to delay the progress of kidney disease depending on eGFR. Likewise, a compensatory tubular function of creatinine and glucose excretion in CKD patients exhibited nonspecific alterations to minimize the renal disease progresses [22]. On the other hand, the reduction of renal function increased the level of EurGF which may misguide that patients with poor renal function were overproducers of the urate. Due to the declining renal function in CKD patients, urate transporters expressed at the proximal tubules cannot achieve sufficient uric acid excretion [23-25]. And more evidence has proved that some uric acid transporters also expressed at the intestinal cells which appear to maintain uric acid homeostasis especially in CKD patients [26-29]. It has been demonstrated that the extra-renal ABCG2 played a compensatory role in the setting of impaired renal function compared with renal urate transporters [30]. Thus, though FEur and EurGF eliminates the effects of other confounding factors which may reflect more on the compensatory residual kidney function in CKD patients and may not be interpreted as the real status of renal uric acid handling [31].

Though the mechanisms of renal urate handling have yet to be fully understood, urate transporter system will help us to explain how these indicators can be modified by CKD. Due to the special status of CKD, the abnormal expression of local stimulator in kidney could affect uric acid excretion, such as PTH, ANGII. With the progress of CKD, glomerular filtration function has become the main influencing factor of uric acid excretion and glomerulotubular imbalance may lead to a significant increase in FEur [32]. The EurGF of residual nephron will be correspondingly compensated. On the other hand, apical URAT1 deletion significantly reduces urate reabsorption whereas ATP-binding cassette subfamily G member 2 (ABCG2) dysfunction affects uric acid excretion slightly that also help to explain the compensatory increase of FEur in severe renal dysfunction.

Some limitations of our study needed to be mentioned. The nature of cross-sectional study makes it hard to establish the causal relationship between eGFR and renal uric acid indicators. And the single urine collection may overestimate or underestimate the actual urinary excretion of uric acid. The clinical correlations also needed to be further clarified. A well-designed prospective study would be helpful for further studies to confirm the value of uric acid parameters. Nevertheless, our study is in line with the real clinical situation, in that many hyperuricemic patients have renal dysfunction. The strict sample collection and proper statistical methods further enhance the credibility of our study. And our results provided a new understanding of the value of uric acid indicators to better guide clinical treatment in CKD patients and provided clinical support for the study of underlying mechanisms.

\section{Conclusion}

In conclusion, our study demonstrated that taking into account the special pathophysiological conditions of patients with CKD, Cur and Flur may be more reliable indicators of hyperuricemia classification although more evidence is needed to support this notion. On the other hand, uric acid may be excreted in other ways when renal function was severely declined, such as the intestinal excretion, suggesting treatment aimed at enhancing extra-renal excretion of uric acid may have clinical value in CKD patients with hyperuricemia.

\section{Abbreviations \\ CKD: Chronic kidney disease; eGFR: Estimated glomerular filtration rate; SUA: Serum uric acid; FEur: Fractional excretion of uric acid; EurGF: Excretion of uric acid per volume of glomerular filtration; UUA: Urinary uric acid excretion; Cur: Clearance of uric acid; FLur: Filtration load of uric acid; HB: Femoglobin; CRP: C-reactive protein; HbA1c: Hemoglobin A1c; ALB: Albumin; LDL: Low-density lipoprotein; HDL: High-density lipoprotein; TC: Total cholesterol; TG: Triglycerides; BUN: Blood urea nitrogen; Scr: Serum creatinine; BMI: Body mass index; Ucr: Urinary creatinine; Ccr: Clearance of creatinine; SNPs: Single nucleotide polymorphisms}

\section{Acknowledgments}

None.

Authors' contributions

HCG and YQZ contributed equally to this work. HCG, JX, ZBY designed the whole experiment. HCG, YQZ, YX, XZ and CSF collected and analysed the data, and provided intellectual content of critical importance to the work described. HCG interpreted the data and wrote the manuscript. JX, ZBY revised the article. All authors read and approved the final manuscript.

\section{Funding}

This research is funded by the Natural Science Foundation of Shanghai (Grant number 17ZR1409100). The founder supports the scientific research with non-profit interests and provides the researcher with remuneration.

\section{Availability of data and materials}

The datasets used and/or analyzed during the current study are available from the corresponding author on reasonable request.

\section{Ethics approval and consent to participate}

Our study was approved by the ethics committee of Huadong hospital affiliated to Fudan University and the protocols were carried out in accordance with the ethical principles for medical research involving human subjects. Written informed consents were obtained from all subjects.

\section{Consent for publication}

Not applicable.

\section{Competing interests}

The authors declare that they have no competing interests.

\section{Author details}

'Department of Nephrology, Huadong Hospital affiliated to Fudan University, No. 221 West Yan'an Road, Shanghai 200040, P.R. China. ${ }^{2}$ Shanghai Key Laboratory of Clinical Geriatric Medicine, No. 221 West Yan'an Road,

Shanghai 200040, P.R. China. 
Received: 18 February 2020 Accepted: 15 July 2020

Published online: 22 July 2020

\section{References}

1. Miyaoka T, Mochizuki T, Takei T, Tsuchiya K, Nitta K. Serum uric acid levels and long-term outcomes in chronic kidney disease. Heart Vessel. 2014;29: 504-12.

2. Toda A, Ishizaka Y, Tani M, Yamakado M. Hyperuricemia is a significant risk factor for the onset of chronic kidney disease. Nephron Clin Pract. 2014;126: 33-8.

3. Ohta Y, Tsuchihashi T, Kiyohara K, Oniki H. Increased uric acid promotes decline of the renal function in hypertensive patients: a 10-year observational study. Intern Med. 2013;52:1467-72.

4. Yan D, Tu Y, Jiang F, Wang J, Zhang R, Sun X, Wang T, Wang S, Bao Y, Hu C, Jia W. Uric acid is independently associated with diabetic kidney disease: a cross-sectional study in a chinese population. PLoS One. 2015;10:e129797.

5. Weiner DE, Tighiouart H, Elsayed EF, Griffith JL, Salem DN, Levey AS. Uric acid and incident kidney disease in the community. J Am Soc Nephrol. 2008;19:1204-11.

6. Roughley MJ, Belcher J, Mallen CD, Roddy E. Gout and risk of chronic kidney disease and nephrolithiasis: meta-analysis of observational studies. ARTHRITI S RES THER. 2015;17:90.

7. Choi HK, Mount DB, Reginato AM. Pathogenesis of gout. Ann Intern Med. 2005:143:499-516

8. Krishnan E. Reduced glomerular function and prevalence of gout: nhanes 2009-10. PLoS One. 2012;7:e50046.

9. Edwards A, Auberson M, Ramakrishnan SK, Bonny O. A model of uric acid transport in the rat proximal tubule. Am J Physiol Renal Physiol. 2019;316(5): F934-47.

10. Boss GR, Seegmiller JE. Hyperuricemia and gout. Classification, complications and management. N Engl J Med. 1979;300:1459-68.

11. Paul BJ, Anoopkumar K, Krishnan V. Asymptomatic hyperuricemia: is it time to intervene? Clin Rheumatol. 2017:36:2637-44.

12. Perez-Ruiz F, Calabozo M, Erauskin GG, Ruibal A, Herrero-Beites AM. Renal underexcretion of uric acid is present in patients with apparent high urinary uric acid output. Arthritis Rheum. 2002;47:610-3.

13. Lytvyn Y, Skrtic M, Yang GK, Yip PM, Perkins BA, Cherney DZ. Glycosuriamediated urinary uric acid excretion in patients with uncomplicated type 1 diabetes mellitus. Am J Physiol Renal Physiol. 2015;308:F77-83.

14. Louthrenoo W, Hongsongkiat S, Kasitanon N, Wangkaew S, Jatuworapruk K. Effect of antituberculous drugs on serum uric acid and urine uric acid excretion. J Clin Rheumatol. 2015;21:346-8.

15. Toyoki D, Shibata S, Kuribayashi-Okuma E, Xu N, Ishizawa K, Hosoyamada M, Uchida S. Insulin stimulates uric acid reabsorption via regulating urate transporter 1 and atp-binding cassette subfamily g member 2. AM J PHYS IOL-RENAL. 2017;313:F826-34

16. Li F, Guo H, Zou J, Chen W, Lu Y, Zhang X, Fu C, Xiao J, Ye Z. The association of urinary sodium and potassium with renal uric acid excretion in patients with chronic kidney disease. Kidney Blood Press Res. 2018;43: 1310-21.

17. Bardin T, Richette P. Impact of comorbidities on gout and hyperuricaemia: an update on prevalence and treatment options. BMC Med. 2017:15:123.

18. Chen MY, Wang AP, Wang JW, Ke JF, Yu TP, Li LX, Jia WP. Coexistence of hyper-uricaemia and low urinary uric acid excretion further increases risk of chronic kidney disease in type 2 diabetes. Diabetes Metab. 2019;45(6):55763.

19. Bellomo G, Venanzi S, Verdura C, Saronio P, Esposito A, Timio M. Association of uric acid with change in kidney function in healthy normotensive individuals. Am J Kidney Dis. 2010:56:264-72.

20. Ruiz FP, Raluy MC, Beites AMH, Lucea ER, Ruiz AA. Analysis of the methods for classifying gout according to renal excretion of uric acid. Revista Espanola de Reumatologia. 1998;25:335-9.

21. Ma L, Wei L, Chen H, Zhang Z, Yu Q, Ji Z, Jiang L. Influence of uratelowering therapies on renal handling of uric acid. Clin Rheumatol. 2016;35: 133-41

22. McPhaul JJ. Hyperuricemia and urate excretion in chronic renal disease. Metabolism. 1968;17:430-8

23. Mandal AK, Mount DB. The molecular physiology of uric acid homeostasis. Annu Rev Physiol. 2015;77:323-45.

24. Merriman TR. An update on the genetic architecture of hyperuricemia and gout. ARTHRITIS RES THER. 2015;17:98.
25. Xu L, Shi Y, Zhuang S, Liu N. Recent advances on uric acid transporters. Oncotarget. 2017:8:100852-62

26. Hyndman D, Liu S, Miner JN. Urate handling in the human body. Curr Rheumatol Rep. 2016:18:34

27. Nigam SK, Bhatnagar V. The systems biology of uric acid transporters: the role of remote sensing and signaling. Curr Opin Nephrol Hypertens. 2018; 27:305-13.

28. Ichida K, Matsuo H, Takada T, Nakayama A, Murakami K, Shimizu T, Yamanashi Y, Kasuga H, Nakashima H, Nakamura T, Takada Y, Kawamura Y, Inoue H, Okada C, Utsumi Y, Ikebuchi Y, Ito K, Nakamura M, Shinohara Y, Hosoyamada M, Sakurai Y, Shinomiya N, Hosoya T, Suzuki H. Decreased extra-renal urate excretion is a common cause of hyperuricemia. Nat Commun. 2012:3:764.

29. Hosomi A, Nakanishi T, Fujita T, Tamai I. Extra-renal elimination of uric acid via intestinal efflux transporter bcrp/abcg2. PLoS One. 2012;7:e30456.

30. Bhatnagar V, Richard EL, Wu W, Nievergelt CM, Lipkowitz MS, Jeff J, Maihofer AX, Nigam SK. Analysis of abcg2 and other urate transporters in uric acid homeostasis in chronic kidney disease: potential role of remote sensing and signaling. Clin Kidney J. 2016;9:444-53.

31. Magoula I, Tsapas G, Mavromatidis K, Katinios A. Single kidney function: early and late changes in urate transport after nephrectomy. Kidney Int. 1992:41:1349-55.

32. Steele TH, Rieselbach RE. The contribution of residual nephrons within the chronically diseased kidney to urate homeostasis in man. Am J Med. 1967; 43(6):876-86.

\section{Publisher's Note}

Springer Nature remains neutral with regard to jurisdictional claims in published maps and institutional affiliations.
Ready to submit your research? Choose BMC and benefit from:

- fast, convenient online submission

- thorough peer review by experienced researchers in your field

- rapid publication on acceptance

- support for research data, including large and complex data types

- gold Open Access which fosters wider collaboration and increased citations

- maximum visibility for your research: over $100 \mathrm{M}$ website views per year

At $\mathrm{BMC}$, research is always in progress.

Learn more biomedcentral.com/submissions 